\title{
USING DESIGN AS BOUNDARY SPANNER OBJECT IN CLIMATE CHANGE MITIGATION PROJECTS
}

\author{
Walter Fernández \\ Accounting and Business Information Systems \\ Australian National University, Australia \\ Birgitta Bergvall-Kåreborn \\ Social Informatics, DBASC, Luleå \\ University of Technology, Sweden \\ Michael Djordjevic \\ Research School of Biological Science \\ Australian National University, Australia \\ Keith Lovegrove \\ Department of Engineering \\ Australian National University, Australia

\section{Sasi Nayar} \\ Aquatic Sciences \\ South Australian Research and Development Institute, Australia
}

\begin{abstract}
Climate change is a growing concern for society and the focus of numerous research initiatives across multiple fields of science. These initiatives often need to capitalize on the cross-specialized knowledge contributed by researchers from very different fields. The diversity of worldviews among key stakeholders requires an effective overall design strategy acting as a boundary spanner object. This study presents an account of the issues faced by a multidisciplinary research project and discusses the suitability of a design approach to help address issues such as equality, empowerment, autonomy, creativity, performance, reduction of innovation cycle times and also provide for the necessary balance between control, speediness and flexibility.
\end{abstract}




\section{INTRODUCTION}

The continued use of fossil fuels, combined with deforestation, urbanisation and agricultural practices, is elevating the concentration of atmospheric $\mathrm{CO}_{2}$ and other Green House Gases (GHGs), which is almost certainly contributing to global warming and ocean acidification (Guinotte et al 2008). This is happening at a time in which our dependency on fossil fuels is significant, approximately $95 \%$ of society's primary energy comes from fossil fuels and of these, oil in particular has limited reserves (Somerville 2007; Witze 2007). In addition, over the next 25 years, increases in both population and affluence will boost global energy demand by more than 50\% (Ölz et al. 2007). Thus, to reduce this dependency and address the adverse effects of fossil fuels consumption on the environment alternatives sources of energy are urgently required (Witze 2007).

The mitigation of the effects of the anthropogenic contribution to global warming requires urgent and concerted action. Unless there is (a) massive investment in, and implementation of, effective, economic, clean, and preferably renewable, energy systems, and (b) greatly improved energy efficiency, the world is on course for an uncertain, unstable, dirty and expensive energy future the ramifications of which are likely to be environmentally, economically and socially challenging (Ölz et al. 2007). To address these concerns, governments have mandated GHG reductions of up to $80 \%$ by 2050 to address climate change and while these dates may seem distant, early decisions are needed to reach them (Stern 2008).

To shift the world's dependence away from fossil fuels such as oil for transport fuel and a range of industrial raw materials, alternative fuels and energy technologies require urgent development. One way to do this is to use a renewable biomass source; this is an attractive proposition for a major agricultural nation such as Australia. Consequently, the Australian Government has set a 20\% target for renewable energy by 2020 (Australian-Government 2008). Terrestrial plants can be used to achieve these goals but this requires effective solutions for conversion of the biomass (e.g. efficient lignocellulosic fermentation or effective pyrolysis) and the diversion of arable land from food to energy production is an increasingly economically and socially questionably notion (Durrett et al. 2008; Hu et al. 2008).

The societal awakening to the problems caused by climate change seems sudden. Yet, scientists have been working for years on different ways to alleviate this problem and today their work continues in many research institutions worldwide. This paper is focused on a research program aiming to produce new and sustainable carbon-neutral energy sources by capitalizing on Australia's natural advantages and know-how. We called this program the BioSolar Initiative. The following sections explain our research problem, the characteristics of the case under study, its context and issues, and propose a design approach to facilitate the management and enhance the outcomes of this kind of initiative.

\section{RESEARCH PROBLEM}

Our project's ultimate objective is to develop an algal-solar industry that will attain multiple climate change mitigation objectives by producing a range of products without using food crops, destroying rainforests or arable land or competing with traditional agriculture for fresh water. In the medium to long term, this project could have national and international importance and will contribute to several areas of knowledge. In the short term, we needed to define a project approach that is 
sensible, efficient and effective. This approach also needs to be easy to communicate to diverse stakeholders, including decision makers and potential partners.

Therefore, we are confronting the issue of integrating different and significant knowledge domains, such as biological science, engineering, information systems, business process modelling, supply chain management, financial modelling, business management and environmental accounting, among others.

The presence of these knowledge domains both enables and impedes innovation. Often the solution of specific issues or problems within particular domains can hinder the success of the overall initiative across the different knowledge areas; thus creating boundaries between specialists (Carlile 2002). Therefore, when working in projects that require multiple knowledge domains, we need to consider the effect of the unavoidable presence of knowledge boundaries between deep and specialized areas. These boundaries are part of the reality of innovation. As Carlile (2002 p.442) puts it, "[t]he irony is that these knowledge boundaries are not only a critical challenge, but also a perpetual necessity because much of what organizations produce has a foundation in the specialization of different kinds of knowledge."

Consequently, the overarching question guiding the project management research component of this initiative is concerned with how we can manage substantial multidisciplinary research projects in order to achieve significant practical outcomes in an incremental, expedient and coordinated manner.

The aim of this paper is threefold: to depict the general aspects of this initiative, to describe the perceived challenges, and to explain a design approach that considers the needs and wants of different constituencies. To describe our study, we adopted a case-centric approach that incorporates the relevant literature at two stages; first, while describing the problem domain and, second, during the description of the proposed approach. The following sections present our problem and current state of ideas with the aim to contribute to the ongoing discussion on multidisciplinary research.

\section{THE BIOSOLAR INITIATIVE}

World-wide concerns about global warming, climate change and pollution have sharpened public demand for sustainable energy solutions. Thus, a considerable effort is required to find and deploy sustainable solutions without derailing economies or sacrificing modern lifestyle. One of these potential solutions can be found in the innovative use of solar energy. Several technologies have been developed to capture solar energy, including the harvesting of sunlight as plant biomass in a variety of first generation "energy" crops. These crops include the use of corn, sugar, soybean and wheat.

The International Energy Agency (IEA) raises doubts over the economic viability of first generation biofuels (IEA 2004). This is because the current biofuel feedstocks such as corn, sugar, soybeans and wheat are perceived as critical food sources for an increasing world population that should not be diverted to energy production. In addition the life cycle analyses of several of these crops do not lead to net energy gains. These factors present an interesting dilemma as arable land is also required for a growing demand for food crops for human consumption (Demirbas 2008). While the diversion of food crops usage to energy production is not the sole reason for spikes in food prices, demand for 
biofuel feedstocks contributes to overwhelm a food supply system already suffering the pressure of surging demand and environmental pressures (Tenenbaum 2008).

In contrast, microalgae represent an untapped and versatile cropping system with distinctive advantages. Microalgae can grow in sea water or waste water that is unsuitable for other purposes (Chisti 2007), thus microalgae can be grown without competing for fresh water or arable land with classical agriculture. With effective $\mathrm{CO}_{2}$ supplementation and non-limiting growth conditions, selected microalgae they can achieve productivities up to ten-times higher than the best traditional crops and forestry systems (Chisti 2007; Chisti 2008). In addition, microalgae can contribute to atmospheric $\mathrm{CO}_{2}$ abatement, indirectly, by minimizing the need of fossil fuels, and directly, by acting as net carbon sequesters (Lehmann 2007). The carbon captured in the char derived from the dry pyrolysis of plant biomass is stable for long periods and the application of char to crops is reported to lead to increases in crop biomass and production (Glaser et al. 2002). Through biotechnology, microalgae can also be manipulated to generate new feedstock sources for pharmaceutical and chemical industries.

Solar thermal technologies and algal harvesting are independent technologies that have been investigated to provide alternative energy sources. By combining solar thermal technologies with algae harvesting and processing, the sustainable production of biofuels such as biodiesel, hydrogen, methane and new feedstock sources for other industries can result. Solar-thermal concentrators can produce temperatures high enough to drive thermochemical reactions to produce carbon monoxide and hydrogen mixtures from algal biomass. Carbon monoxide and hydrogen are the basic feedstocks for processes producing a range of liquid fuels(Lovegrove et al. 2004).

The development and industrial application of these technologies is the end-goal of the BioSolar Initiative. To achieve this objective we need to combine best-of-breed microalgal and solar-thermal technologies while remaining open to complimentary technologies that could be coupled to the system. By doing so, this initiative will produce a number of solutions that will contribute to the pressing problem climate change mitigation. To illustrate this approach, one of these projects is presented next.

\section{THE ALPHA PROJECT: HARVESTING SEWAGE}

The Alpha Project arose from the need to remove nutrients from effluent wastewater and the recognition that the growth of microorganisms in this water could form the basis of a significant second generation biofuel industry. The aim of this project is the development and optimization of systems to generate microalgal biomass, grown in urban wastewater, as a feedstock for gasification (see Figure 1). 


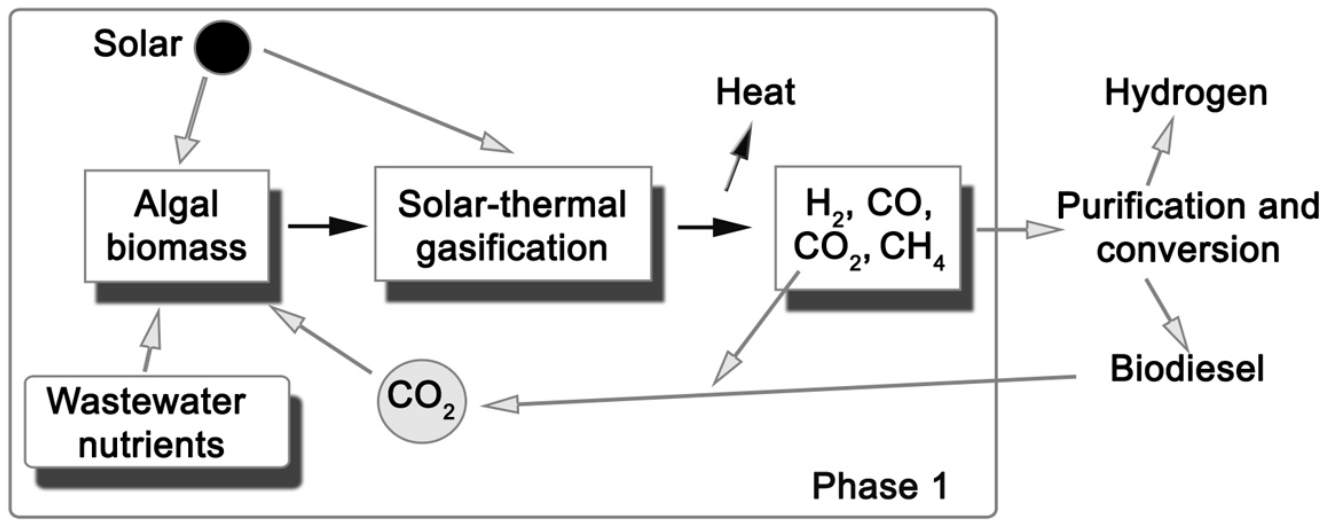

Figure 1: Gasification of algal biomass. Phase 1 represents the boundaries of the Alpha Project.

From the biology perspective, this project will isolate and harness robust, fast growing strains of Australian microalgae adapted to growth in the wastewater at the site of our industry partner. The work required in this area has many elements, including the following: assessment of benefits and needs arising from the biological scavenging of environmentally damaging inorganic nutrients from the wastewater, selection and optimization of select strains to match annual variations in environmental conditions, and development of specialized production systems and new biotechnologies to obtain cell densities optimized for the proposed research.

Another important aspect of this project is the exploration of advantages of the "wet" pyrolysis process under "supercritical" conditions. The gasification of the microalgae will involve using pressurized, supercritical water at temperatures greater than $660^{\circ} \mathrm{C}$ that can be generated using Solar Thermal Concentrators. The gasification process will generate $\mathrm{H}_{2}, \mathrm{CO}$ and other gases (Figure 1) in a carbon neutral process that can include the looping back of $\mathrm{CO}_{2}$ into the microalgal production process. The gases produced will have multiple uses: storage of solar energy, the production of biofuels or as an industrial feedstock (e.g. for ammonia or methanol production). These downstream processes are beyond the scope of the alpha project but are part of our longer term goals.

The Alpha Project combines the wastewater management technology of our industry partner; the expertise in microalgae selection, pure culture, optimization, manipulation and mass culture of the South Australian Research and Development Institute and ANU's Research School of Biological Sciences, and ANU's world-leading skills in solar concentrating systems and engineering. The project will undertake the R\&D necessary to synergistically combine these interdisciplinary skills and techniques to achieve cost effective microalgal feedstock production for use as a renewable energy source. While this opportunity is significant to our long term research objectives, it also presents a number of challenges.

\section{THE OPPORTUNITY AND ITS CHALLENGES}

In terms of biological science, we are starting from a solid base. However, the key challenge remains in the industrialization and commercialization aspect of this technology. We need to move 
the project from the controlled environment of the laboratory's bench to the industrial and commercial environment. This task is perceived as both complex and urgent.

To achieve the transformation from laboratory to product delivery, we have to confront a number of important issues such as scalability; automation; business processes analysis and design; management of development activities; integration and coordination of multiple concurrent projects; skill development for scientists, engineers and technical personnel; design and development of information systems, information technology, and special equipment; automation and remote management systems; identification of complementary algal technologies; environmental accounting assessments, development of replicable and adaptable production protocols, implementing effective supply chains, and so forth.

We have a great opportunity in front of us and with it a significant challenge. Many minds, from many fields, with different worldviews and agendas, will need to work in a coordinated manner, addressing priorities and developing a long term plan of action that is efficient, effective and flexible enough to accommodate the uncertainties of innovative endeavours. The development of commercially viable new products requires considerations related to both technology and market that must be incorporated into the design of the innovation (Dougherty 1992).

The overall planning of this initiative is a difficult and complex task because our knowledge of the problem domain is far from perfect and its context plagued with uncertainties and potential for miscommunication. Consequently, the planning tools need to be flexible and evolutionary, adopting a performing view of project knowledge in which we perceive "knowledge not as static or given, but as a capability produced and reproduced in recurrent social practices" (Orlikovski 2006 p.460).

Given the performing nature of this project, we need an effective way of designing a new industry in a manner that is incremental in nature and facilitates the end-to-end efficient and effective management of the project. Coordination and collaboration seems critical from conceptual design to prototype design and to product and services design, but, as earlier mentioned, to be effective the ideal approach also needs to be agile and modifiable.

We need to develop technology in a social and political context. Therefore, to achieve effective levels of coordination and collaboration while remaining agile and responsive to environmental changes, we must take into consideration demands from business, government and academic stakeholders, among others. As a result, a suitable methodology that considers human and technical aspects of the project must be able to work across different fields of human endeavour.

In selecting a suitable approach, we considered the needs for the methodology to act as a scaffold to the generation of knowledge and physical artefacts. Orlikovski (2006) describes the notion of scaffolding as a useful metaphor to studies of performative knowledge and human agency. By adopting this mindset, the overarching project methodology can be used to extend, complement, link, stabilize, reconfigure and transform human agency (Orlikovski 2006).

The next section describes a method that has been successfully used in Europe to manage innovative projects and that appears promising in addressing our significant challenges. 


\section{FORMIT: DESIGNING COMPLEX AND INNOVATIVE SYSTEMS}

During the initial planning stage of the BioSolar initiative we understood that to succeed we needed to produce a system that considers the human aspect of the technology. This design principle was perceived as critical to enhance the effectiveness and implementation of the technology and some guidance was found in the ISO 13407:1999 Human-centred design process for interactive systems. This standard describes aspects of software and hardware systems so project managers can understand the basic issues involved when including human-centred activities throughout a development life-cycle. While this was certainly a step forward, ISO 13407:1999 does not cover in detail the practical issues of conducting human-centred design, the necessary methods and techniques.

The initial handle on how the BioSolar initiative could be managed was found in FormIT (BergvallKåreborn et al. 2007a; Ståhlbröst et al. 2007a). The FormIT approach was originally created to develop IT-based artefacts and services that takes a "human centred" (Kling et al. 1998) approach to design. FormIT aims to guide and facilitate the development of innovative services that are based on a holistic understanding of people and their behaviour, grounded in needs and wants that stakeholders experience as relevant. FormIT takes seriously issues such equality, empowerment, autonomy, and control in relation to actual use situations; that is, the whole system in development and in operation. Proactive consideration of these issues is critical in cross-boundary programs demanding (a) high levels of collaboration and synergy, (b) flexibility to enhance creativity and innovation, and (c) controls to facilitate progress in a coordinated and planned manner.

Three theoretical streams inspired FormIT: Soft Systems Thinking (SST), Appreciative Inquiry and Needfinding. SST (Checkland et al. 1986; Checkland et al. 1999) provided the assumption that changes can only occur through changes in mental models. This implies that we need to understand both our own as well as other stakeholders worldviews and we need to be clear about our interpretations and the basis on which they are made (Bergvall-Kåreborn et al. 2007b; Ståhlbröst et al. 2007b). Hence, we aim to interpret and understand situations through an iterative and interactive process with stakeholders. This concept fits well with the principles stated in the BioSolar initiative; we strongly believe that complex system with multiple stakeholders cannot be successfully developed in the isolation of the laboratory's bench. We also need to define the meaning of success for the project, as this definition is a social construction that facilitates the project's outcome (Thomas et al. 2008).

Appreciative Inquiry (Cooperrider et al. 2004; Cooperrider et al. 2005a; Cooperrider et al. 2005b; Norum 2001) has encouraged the Swedish author(s) to start the development cycle with identifying different stakeholders' dreams and visions of how technology can improve, and support the lives of people. This includes a focus on opportunities, related to specific trends, contexts, or stakeholder groups, and, on the positive and life-generating experiences of people. This way of thinking is closely aligned with the philosophy behind SST since it also highlights the importance of people's thoughts about themselves and the world around in design situations. Hence, instead of starting the process by searching for problems to solve in a situation, we identify what works well and uses this as a basis for design. In the BioSolar initiative we have identified technologies that work well (algal technologies and solar thermal) as the starting point for our design.

Needfinding (Bergvall-Kåreborn et al. 2007a), is about focusing on stakeholders needs throughout the development process, and to use these as a foundation for the requirement specification. Patnaik 
and Becker (1999) states that the main motivator for the needfinding approach is that needs are not highly influenced by trends, hence they are more long lasting. Therefore, the project must include and provide adequate resources for the needs elicitation process (Kankainen et al. 2003a; Kankainen et al. 2003b; Tiitta 2003). In our perspective, identifying opportunities is the basis for appreciating needs since needs are opportunities waiting to be exploited.

FormIT also strongly emphasize the importance of the first phase in the development cycle usually referred to as analyses or requirements engineering. Since this phase creates the foundation for the rest of the process, errors here becomes very hard and expensive to correct in later stages. Following the human centric approach, this is also the phase where stakeholders make the strongest contribution by actually setting the direction for the design, rather than mainly responding to half finished prototypes. However, since stakeholder needs and requirements can change as they gain more knowledge and insights into possible solutions, it is important to continually reassess these needs and to ensure that needs correlate to given requirements.

In conclusion, FormIT is an iterative method where continuous interaction with stakeholders is an understood prerequisite. The basic idea is that knowledge increases through iterative interactions between phases and people with diverse competences and perspectives. In this way, knowledge increases through dialogue between participants (Ståhlbröst et al. 2006). The cross-functional interaction enables the processes of taking knowledge from one field to another to gain fresh insights, which then facilitates innovative ideas. The shared understanding of the situation informs and enriches the learning processes and thus facilitate changes in perspective and lead towards innovative design-processes (Holst et al. 2006). This, in turn, increases our qualifications to design systems which answer to stakeholder needs. A more detailed description of the method follows.

\section{The FormIT Method}

FormIT can be seen as three interconnected evolutionary cycles (Discover Opportunities, System Design, and Experience Evaluation) where the design becomes increasingly clearer, while the attention of the evaluation broadens from a focus on concepts and prototype to a holistic view on the use of the system. Within each of the cycles three basic phases, are repeated (Discover Needs; Design; and Evaluate). The full methodology includes two additional phases (Planning and Commercialisation), as seen in Figure 2.

Planning stands for planning the intervention as a whole and here it is important to gain as much information as possible about the underlying circumstances for the project, its aim and scope. During planning different perspectives on the project need to be appreciated while constraints and boundaries need to be accepted. Three important perspectives that need to be considered and combined are the human, technological and business perspectives of a project. It is common that different stakeholders assign different priorities to each of these perspectives; there is nothing wrong with this as long as everyone understands the importance of all three and how they contribute to, and interact with, each other.

While planning the intervention can be seen as the start up phase of the project as a whole, much of the guidelines and lessons learned in relation to this phase can also be applicable in the planning of the subsequent phases. In a large, complex and multidisciplinary project such as the one described in this paper, the planning phase is extremely important since divergent views on the aim and scope of the project, as well as on roles, responsibilities, and authority can put the whole project at risk. 
Hence, before leaving this phase a sense of "accommodation" (Checkland et al. 1999) concerning these issues need to reached between key stakeholders.

The Commercialisation work need to be integrated into the development work but is often treated as a separate project where the aim is to implement the system and to introduce it to the market. While the commercialisation effort and focus is greater nearing project completion, this phase is definitely not a passive sink collecting the results of previous cycles. We acknowledge that system design cycles inform commercialisation and are also informed by commercialisation issues, this is critical to facilitate effective end-to-end alignment. Also lessons learned from commercialisation experiences inform the planning of future systems. However, as this paper focuses on the planning phase and the subsequent design cycles, the commercialisation phase is presented for completeness purpose only.

The following subsections provide a short description of the character and main activities of each one of the three cycles.

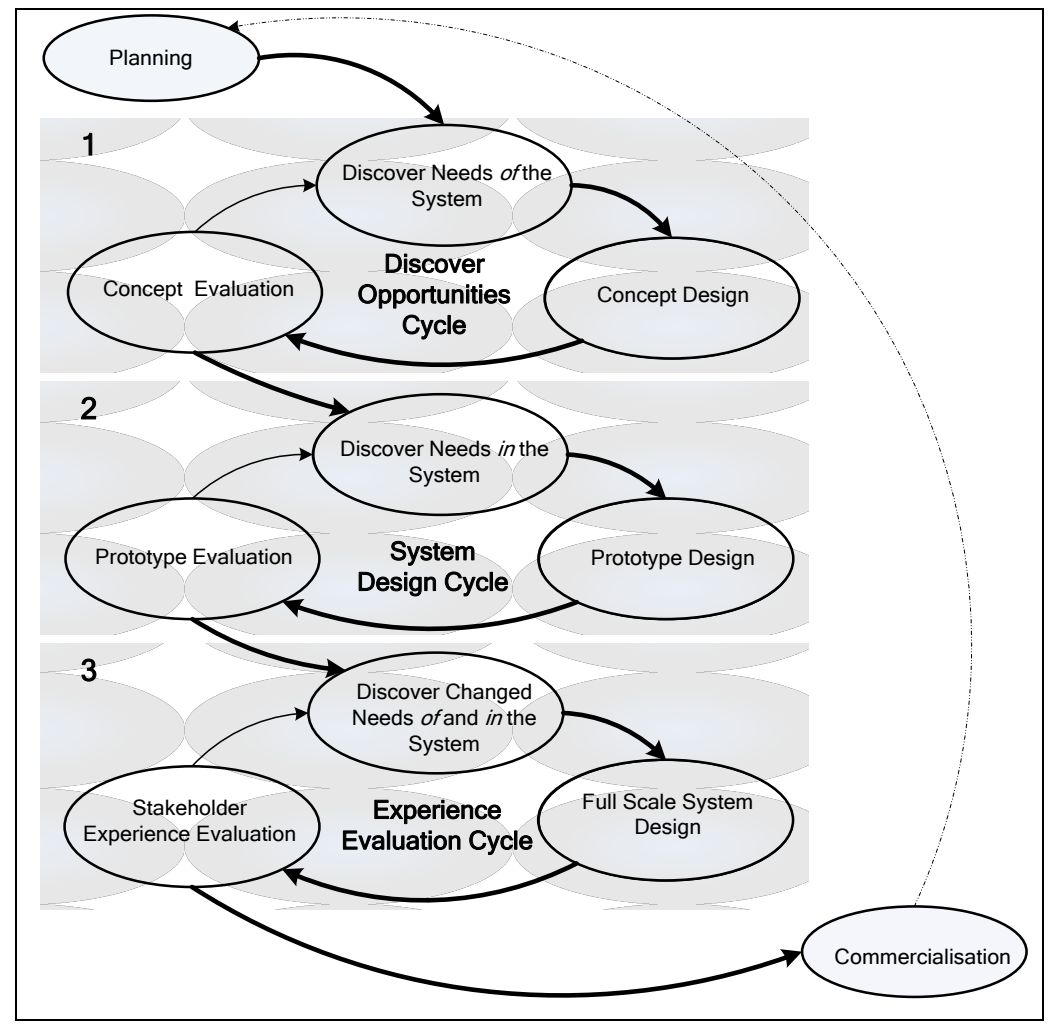

Figure 2: The FormIT Process for Innovation Development. 


\section{The First Cycle - Needs of the system}

The first cycle focuses on discovering the basic needs that different stakeholders have of the system. These are the needs that motive them to buy and use a particular product or service. Following the language of Soft Systems Methodology these needs are part of the "Weltanschauung" (Checkland et al. 1986), the worldview that makes the service meaningful to use. The needs of the system may vary and take different forms depending on stakeholder, context and situation. The challenge in the discovery phase of the first cycle is thus to identify the key needs of the system, and the different expressions they may take. This is done by obtaining a rich picture of different stakeholders, their behaviour, attitudes and values. When this is achieved, the needs are translated into design concepts in the form of scenarios or mock-ups. By doing that, the focus shifts from the discovery phase to the design phase. The aim of the design phase is to develop new and innovative concepts based on the data form the discovery phase. The concepts need to be detailed enough for the stakeholders to understand the basic objective and functions of the system. From here, the focus shifts again, this time from the design phase to the evaluation phase. The aim of the evaluation of the first cycle is to make sure that the stakeholders agree with the basic objectives of the developed concepts. This means relating the basic objectives and functions of the system to the identified needs of the system to make sure that these are consistent. If not, this cycle needs to be re-iterated until such coherence is achieved.

\section{The Second Cycle - Needs in the system}

The second cycle starts with the process of identifying stakeholders' needs in the system. That is, what needs in the finished system are important for stakeholders. As in the first cycle, this is done through a variety of data gathering methods, such as interviews and observations. The challenge in this second cycle is to separate between needs of the system (visions and motivations) and needs in the system (goals, processes and functions). One way of doing this is to keep the concept design, with key needs related to it, visible for the stakeholders during the data collection activities, so it is possible to relate to these during the discussions. When the data collection no longer generates new insights and findings, we consider that we have reached saturation and the focus again shifts to the design phase. However, in the second cycle the design of the system broadens to include basic functions, work flows, and interfaces. The prototype or design need to be detailed enough for the stakeholders to understand and be able to experience how the final system will look and feel. This leads us to the evaluation which is centred on structure, processes, activities and information follows in the second cycle. This includes questions and analyses concerning how different subsystems need to be integrated, how they affect each other and the system as a whole. The evaluation is focused on the interaction between the parts and the whole.

\section{The Third Cycle - Needs of and in the system}

The third cycle starts by analysing the results from the prototype evaluation in order to discover changes in the needs of and in the system. Small changes and adjustments in the needs are quite common, especially in relation to the needs in the system, as the system develops and stakeholders' understanding of structure, content, workflow and interface deepens. Based on these changes, changes in the design of the system also take place, as well as general development work to finalize the system as a whole. When this is done the last evaluation phase takes place and now the evaluation is focused on the relation between the system and its users. Stakeholder experiences 
goals are primarily subjective qualities and concern how a system feels to a stakeholder. They differ from more objective performance goals in that they are concerned with how stakeholders experience the system and its performance and how useful they consider the system to be rather than assessing how efficient or productive a system is.

\section{FORMIT IN ACTION}

As discussed, each critical cycle is divided in three phases that iterate until the cycle is successfully completed. This section briefly describes a number of recommended actions and the state of our knowledge regarding potential activities to be conducted in future interventions in the BioSolar initiative and its projects.

\section{Initial Planning}

As in every project, we have found that it is highly important to gain a common perspective of what the main purpose of the project is (Ståhlbröst et al. 2005). This can be difficult to accomplish since project participants usually want to make contributions to many different areas. In large, complex and multidisciplinary projects this is particularly challenging since it can be hard for participants to grasp the project as a whole as well as to fully understand the more detailed work tasks of stakeholders from other disciplines (Carlile 2002). It is therefore important to support a communicative approach that build trust and confidence between the stakeholders (Ståhlbröst 2006) and to find ways of illustrating how the different parts of the project relate to each other. For this end, we could adopt PAWDAC (Bergvall-Kåreborn et al. 2004) or Critical Systems Heuristic's boundary questions (Bergvall-Kåreborn 2006; Ulrich 1987; Ulrich 1998). For example, using PAWDAC would involve discussing and reaching consensus related to the following questions: Process: The key process to be carried out in the project as well as the main sub-processes and how they are related to each other. The timeframe of the project and critical milestones.

Weltanschauung: The motivation with the project, as well as its purposes and goals. The problem or opportunity that the project aims to contribute to and the background and needs that formed the project idea?

Affectees: The beneficiaries and victims of the project.

Decision-maker: Those with authority and responsibility over the project and with prime concern for its performance. Power relations that are of importance to consider and how these can have influence on the intervention.

Actors and other resources needed: What competencies and resources are important to involve in the process? What technology does the project require? Does this technique exist today or will it be developed within the project?

Boundaries and Constraints: What in the context might influence on the intervention and what, in the intervention might influence the context

When these questions has been discussed and agreed upon, the first phase of the FormIT process, the discover needs phase, can start.

\section{Phase One in each cycle: Discovering the Needs of the BioSolar system}

This phase is repeated in all three cycles. In the first cycle it is called discover needs of, in the second cycle it is called discover needs in, and in the third cycle it is called discover needs of and in 
(as seen in Figure 2). But the focus is slightly different in the different cycles. In the first cycle the aim is to gain insight into the different basic needs that different stakeholders have of the BioSolar system.

To do this we plan to use a mixture of data collection methods, including focus-group interviews, individual interviews, story telling, observations, formal documents, etc. In both focus-group interviews and the individual interviews we will ask the participants to tell stories that reveal their view on their present and future situation and how the BioSolar system, will help them to make this transformation. These stories will include stories based on their positive experiences related to their every day situation and technology usage. Focusing on past, present, and future situations instead of present problems and existing technological solutions, is important to generate a positive and creative atmosphere in the group. This atmosphere combined with the focus group interview technique stimulates the stakeholders to generate innovative ideas and visions together in a conversational mode. In these conversations, users become inspired; hence, they stimulate each other to go beyond their own frame of mind by developing ideas generated by others. This produces a fruitful and interesting snowball effect, which helps all group members to participate actively during the discussion. In the first cycle we plan to have more heterogeneous and non-established groups since this creates an understanding and knowledge sharing between existing groups and subjects within the project. It also allows for different views and ideas to cross-fertilize and create new and innovative ideas. In the second cycle we will use more homogenous and established groups because this facilitates the discussion of in-depth questions within a particular field or subject.

Since it sometimes can be complicated to encourage participants to tell rich stories in the mode, and depth, that is needed for eliciting needs in group discussion, we will also use individual interviews in order to focus on, and excavate, on specific issues or stories expressed by single participants in the group interviews. To merely focus on one single participant in a group interview might lead to the feeling of not being fully included among the other participants. In addition, focusing on one person's story and digging into that can result in a feeling of being pointed out in front of the other participants. Individual interviews will also be used when the area of concern is of sensitive character, such as confidential information that might be of value for the project.

Our experience is that appreciating strengths and dreaming of the future is difficult for most people because they are stuck in present problems and in their picture of currently existing technological possibilities. To stimulate this 'shift to the future' we will use scenarios as stimuli in two different ways: we will present scenarios for the stakeholders in order to help participants get started in their process and will also ask them to describe a scenario to us.

The usage of stimuli material, such as scenarios or mock-ups, needs to be considered in depth. We have found that stimuli material can have a noticeable impact on the topics being elaborated on in the groups. The stimuli material can smooth the progress of the discussions and we have also used it to fuel discussions when they have started to diminish. In these situations, the material can boost the discussions and the focus-group participants' imagination; hence, the respondents become aware of new needs, and more possible solutions that they had not been aware of previously. However, the usage of stimuli material is not risk free, it can also steer the discussion away from revealing the critical needs of the stakeholders. Thus, to carefully consider and try to imagine the impact of the stimuli is of utmost importance if a high level of validity is desired in the study. 
In addition, experience in Sweden shows that it is necessary to have a blend of competence among the moderators facilitating the interviews, since respondents sometimes ask important questions about a certain technology that need to be understood for the discussion to develop.

\section{Phase Two in each iteration/cycle: Design the BioSolar system}

The aim of this phase is to design and develop innovative concepts on the basis on the identified needs from the earlier phase. The design phase is also carried out in all the three iterations. In the first iteration it is called concept design, in the second Prototype design and in the third it is called Full Scale System Design (as seen in Figure 2). So far, we have focused on the conceptual design that is part of the first cycle of the FormIT process and the cooperation between different stakeholders to ensure that knowledge is shared both across and within competence areas.

Based on our research, we have found that, to ensure that the final solution answers to stakeholders' needs and not merely reflect what is technically possible; a close interaction between stakeholders representing the human, technical, and business perspective is needed. However, this does not mean that all stakeholders need to be involved in all the stages of development, but that the cooperation should build on mutual communication around these perspectives when designing the system. The objective is to ensure that the gained knowledge from earlier stages is guaranteed to be included and considered in the final design.

In this phase, the known needs, as well as identified strengths and dreams, form the basis for the vision of the system that takes form here. Usually a basic idea of the future solution has started to take form, hence the idea will be elaborated on and expressed both textually, in the form of key concepts, and pictorially, in the form of user stories, scenarios, or mock-ups of the system. Broadly speaking, there are two types of design; conceptual and physical. Conceptual is concerned with developing models that captures what the product will do and how it will behave, while the latter is concerned with details of design such as chemical processes, innovative use of solar-thermal energy, work flows or security systems.

In the BioSolar initiative many different concepts need to be designed representing everything from methods of growing the microalgae and developing it into different products to information systems that facilitate and control these processes, as well as managing the project as a whole and of the production site once the project is implemented. All these concepts then need to be clustered and discussed in order to generate new innovative solutions by relating diverse concepts together, but also in order to understand how different key concepts fit together into a meta-model. From the selected concepts requirements are then generated and from the requirements the first prototypes are designed and refined. Through the design phases it will be important to continuously assess the design outcomes with the needs representations from the previous phase.

In order to communicate the idea of a product or service we have found in previous projects that different types of visualizations are very powerful, including the following:

Storyboarding - a series of drawings that shows how the user might progress through a task using the intended design.

Scenarios - an informal story description that describes the tasks the user shall do when s/he uses the design. These stories shall be closely related to the stakeholder's contexts and expected behaviours; further, they shall be related to the goal, or needs, that the stakeholder have expressed); Use cases - a representation that focuses on the interaction between the stakeholder and the system rather than specific user tasks. The use case scenario represents one possible path of behaviour. 
Essential use cases - a combination of use cases and scenarios. This is a structured story consisting of user action and a step-by-step description of the responsibility of the system.

Paper prototypes, mock-ups, card-based prototypes - ways to design the system and present it in sketches where each sketch can represent a screen or a view of the system.

As the process iterates through the model, the key concepts and pictorial expressions of the system will be developed into prototypes and, later, a finished system. The challenge here is to convince the systems developers and technical engineers to consider the list of prioritized needs as a starting point for the vision and then the functional requirements and technical specifications. Since many developers and engineers are unfamiliar with this way of working, they often want to skip this part and go directly to the requirements and specifications.

\section{Phase Three in each cycle: Evaluation of the BioSolar system}

As per the previously described phases, this phase is carried out in all three cycles. It is called concept evaluation in the first cycle, prototype evaluation in the second, and in the third it is called stakeholder experience evaluation (see Figure 2). The goal of this phase is to produce a thorough evaluation of the system to determine if further iterations are required within a particular cycle before proceeding to the next cycle (or to commercialisation in the case of the third cycle).

In this phase, stakeholders are encouraged to give their impressions of the system that has been developed based on stated needs. At this point, the system can have different forms dependent on where in the development process the system is. In the first cycle, the initial evaluation process completes the first iteration of the cycle by evaluating system concepts, or ideas, in relation to the discovered needs. Yet, this is not just a simple verification exercise; the evaluation also aims to identify new and unexplored needs, or modification of needs. When these evaluations and investigations do not give any new insights about stakeholders' needs of the service, the next cycle can start.

In the second cycle, the focus is on evaluating a prototype of the system related to stakeholder needs in the system, hence the focus is on relationships between parts of the system and the system as a whole concerning aspects such as processes, structures, activities, and information flows. Also in this phase, the process is iterated until no new insights are identified.

The third cycle focuses on combining users' needs of and in the system. Then the system is developed into a full scale system; here the focus is on how the system actually works and fits its context of use. For the development project to be successful, ownership of the system must be handed over to and accepted by the involved stakeholders. In this process, the participants might need to change their traditional way of working and acting as if a long-lasting and substantial change has occurred. Thus, we need to consider process change management requirements as one of the deliverables of the design process.

Based on our experiences from working in IT innovation projects, we have found that determining what methods to use when evaluating innovative system can be complicated. One aspect to consider here is the characteristics of the system or subsystem. Since the BioSolar system consists of many different subsystems of chemical, technological, ecological, economical, business and social nature the system need to be evaluated both on an overall level covering all aspects and on a subsystem level with particular focus on the aspects governing a specific subsystem. Also, aspects such as 
wether the system or sub-system under consideration is a product or a service will affect the evaluation and its criteria.

The evaluation process enables the discussion among stakeholders as per how the concepts, prototypes, or final solution can be related and refined to answer to the needs identified in the earlier phases. Hence, the issues that need to be dealt with here are:

- What the approach and purpose for the evaluation is.

- What the main question that needs to be answered is.

- Should the evaluation be of summative, formative, or interactive character

- What kind of data is expected from the evaluation, qualitative or quantitative

- Define what methods to use in the evaluation; interviews, logs, surveys, observations in relation to the purpose

- Study the context to determine what, in the context, that can have influence on the evaluation results

- $\quad$ Create questions, observation schemas or other preconditions for the evaluation. At this stage develop questions on the basis of the identified needs and requirements

- Define the number of stakeholders and stakeholder groups and selection criterions such as age, gender, occupation, and so forth

- Define what the characteristics of the innovation are. Identify important "has to" in the evaluation, such as; when the test has to be done, the duration of the test, the character of the interaction, what a natural behaviour around the innovation is, degree of participation and so forth

To sum up, the focus for this stage varies dependent on where in the development process the innovation is. In the first cycle, the focus is on elaborating with stakeholder needs of the system, while in the second cycle the focus is on prototype level and stakeholders needs in the system. In the last cycle we focus on user experiences and here the main aspect is to hand over the system to the various stakeholders and to evaluate that all important roles, responsibilities and authorities needed to run the system has been defined and handed out. The objective here is to gain insight into stakeholders' needs of the system combined with their needs in the system.

\section{CONCLUSION}

In this paper we presented an on-going project, providing a glimpse at the complexity involved. We posed that collaborative projects with multiple stakeholders and different worldviews require careful management. We also argued that in managing projects in which significant collaborative innovations must be deployed, managers must pay special heed to the human aspects of the project in addition to the technical aspects. In this way, we do not perceive a dichotomy between technical and social considerations, but rather a necessary integration of these aspects.

Hence, we needed a methodology that allows for flexibility and that foster creativity and understanding among stakeholders. We believe that a successful design methodology must provide the basic elements and processes necessary to produce the system in an efficient and effective manner. We stated that FormIT, a methodology used successfully to develop IT innovation, appears suitable for the BioSolar initiative. FormIT seems able to handle some of the identified problems and to provide the basis for further development of the innovation. 
The paper described the cycles in the process and gave example of potential techniques to elicit requirements, to facilitate and to verify the design. Furthermore, because the design method has a strong and coherent philosophical approach we suggest that it can act as a guide to the overall project strategy, providing a system of belief appropriate for complex projects concerned with the development of innovative green-field industries. The methodology is based on a holistic understanding of the problem domain and allows for evolution and flexibility while keeping the project grounded in the needs and wants of key stakeholders.

The paper is limited in many ways, including the discussion of competing design approaches, a review of the innovation literature, the lack of a defined research question or problem, and a discussion of academic politics and its role in the development of science and industry. Also, the method proposed in this paper need to be evaluated in different contexts before they can be generalized to a wider population of multidisciplinary research projects.

The paper contributes to increase the understanding of issues and barriers to multidisciplinary research projects and to the literature in complex systems development, project and program management, and design science. We position this paper not as a definitive answer but rather as a boundary object devised to focus the development of a shared vision of problems and solutions (Gasson 2006).

The presented design method provides the general strategy for managing the project but, as with any complex project, both the method and the project evolve in action (Fitzgerald et al. 2002; Latour 1987). We are aware of the need to apply the method as a scaffolding to build project knowledge and to allow the efficient and effective progress of the project. Our intention is not to stress the formality of the approach but rather its potential for flexibility and adaptability in use. As Berg (1997 p.406) stated, "[t]he formal is symbolic, clean, abstract, homogeneous; the empirical is messy, heterogeneous, concrete, and not (to be) ordered within one single scheme. The formal is the representation, the map; the empirical is the represented, the terrain."

We do not claim that the work in methodology design has been completed. It will remain work-inprogress as more ideas emerge and new activities need to be conducted to let the terrain shape the map that will shape the terrain. Integrating FormIT to a general project management framework requires more empirical work and further research. Yet, the conceptualization of design cycles, the simplicity and consistency of the phases, and our perceived compatibility with the philosophical approach offered by FormIT provide a good starting point for our project.

Finally, from the IS perspective we are humbled by the opportunity to contribute to multidisciplinary research preoccupied with climate change. We also recognize that more work is required and that Information Systems can contribute in many ways to alleviate this critical problem. As Stern (2008 p.33) said, "[i]t is hard to imagine a more important and fascinating problem for research. It will involve all our skills and more, and it will require collaboration across disciplines." We entirely agree.

\section{REFERENCES}

Australian-Government "2007 Australia’s Greenhouse Emissions Trends 1990 to 2008-2012 and 2020: Tracking to the Kyoto Target," Department of Climate Change, Canberra, pp. 1-20. 
Berg, M. "Of Forms, Containers, and the Electronic Medical Record: Some Tools for a Sociology of the Formal," Science, Technology, \& Human Values (22:4) 1997.

Bergvall-Kåreborn, B. "Diversity Is In the Air - It Is Time to Challenge Our Weltanscauung," Systemist

(28:2) 2006, pp 13-25.

Bergvall-Kåreborn, B., Holst, M., and Ståhlbröst, A. "Creating a New Leverage Point for Information Systems Development," in: Advances in Appreciative Inquiry - Designing Information and Organisations with a Positive Lens, M. Avital, R. Boland and D. Cooperrider (eds.), Elsevier, 2007a, pp. 75-95.

Bergvall-Kåreborn, B., Mirijamdotter, A., and Basden, A. "Basic Principles of SSM Modelling: An Examination of CATWOE from a Soft Perspective," Systemic Practice and Action Research (17:2) 2004, pp 55-73.

Bergvall-Kåreborn, B., and Ståhlbröst, A. "The Elusive Nature of User Needs in Existing Information Systems Literature," Proceedings of the 8th IBIMA conference - Information Management in the Networked Economy, Ireland, Dublin, 2007b, pp. 479-487.

Carlile, P.R. "A Pragmatic View Of Knowledge And Boundaries: Boundary Objects In New Product Development.," Organization Science (13:4) 2002, pp 442-255.

Checkland, P.B., and Davies, L. "The Use of the Term 'Weltanschauung' in Soft Systems Methodology," Journal of Applied Systems Analysis (13) 1986, pp 109-115.

Checkland, P.B., and Scholes, J. Soft Systems Methodology in Action: A 30-Year Retrospective John Wiley \& Sons, New York, 1999.

Chisti, Y. "Biodiesel from microalgae," Biotechnology Advances (25:3) 2007, pp 294-306.

Chisti, Y. "Biodiesel from microalgae beats bioethanol " Trends in Biotechnology (26:3) 2008, pp 126-131.

Cooperrider, D.L., and Avital, M. (eds.) Advances in Appreciative Inquiry, Constructive Discourse and Human Organisation. Elsevier, Oxford, 2004.

Cooperrider, D.L., and Whitney, D. Appreciative Inquiry - A Positive Revolution in Change BerrettKoehler Publishers

San Francisco, 2005a.

Cooperrider, D.L., Whitney, D., and Stavros, J.M. Appreciative Inquiry Handbook Berrett-Koehler Publishers, San Francisco, 2005b.

Demirbas, A. "Biofuels sources, biofuel policy, biofuel economy and global biofuel projections," Energy Conversion and Management (49:8), August 2008 2008, pp 2106-2116.

Dougherty, D. "Interpretive Barriers to Successful Product Innovation in Large Firms " Organization Science (3:2) 1992, pp 179-202.

Durrett, T.P., Benning, C., and Ohlrogge, J. "Plant triacylglycerols as feedstocks for the production of biofuels," The Plant Journal (54) 2008, pp 593-607.

Fitzgerald, G.B., Russo, N.L., and Stoltermane, E. Information Systems Development: Methods-InAction McGraw Hill, Maidenhead, UK., 2002.

Gasson, S. "A genealogical study of boundary-spanning IS design," European Journal of Information Systems: Special issue: action in language and organisations 15), 26 2006, p 1. 
Glaser, B., Lehmann, J., and Zech, W. "Ameliorating physical and chemical properties of highly weathered soils in the tropics with charcoal - a review" Biol Fertil Soils (35) 2002, pp 219230.

Guinotte, J., and Fabry, V. "Ocean Acidification and Its Potential Effects on Marine Ecosystems," Annals of the New York Academy of Science (1134) 2008, pp 320-342.

Holst, M., and Mirijamdotter, A. "Interaction in Cross-Functional Team Work: Making Sense through the POM Model," Systems Research and Behavioural Science (Accepted with amendments) 2006.

Hu, Q., Sommerfeld, M., Jarvis, E., Ghirardi, M., Posewitz, M., Seibert, M., and Darzins, A. "Microalgal triacylglycerols as feedstocks for biofuel production: perspectives and advances," The Plant Journal (54) 2008, pp 621-639.

IEA "Biofuels for Transport: An International Perspective," IEA (ed.), International Energy Agency, Paris, France, 2004.

Kankainen, A., and Oulasvirta, A. "Design Ideas for Everyday Mobile and Ubiquitous Computing Based on Qualitative User Data," in: User Interfaces for all, N. Carbonell and C. Stephanidis (eds.), Springer-Verlag, Berlin, 2003a, pp. 458-464.

Kankainen, A., Tiitta, S., and Rantanen, M. "Exploring everyday needs of teenagers related to context and presence aware mobile services," proceedings of Human Factors in Telecommunications, 2003b, pp. 19-26.

Kling, R., and Star, S.L. "Human Centered Systems in the Perspective of Organizational and Social Informatics," Computers and Society (March) 1998, pp 22-29.

Latour, B. Science in Action: How to Follow Scientists and Engineers through Society Harvard University Press, Cambridge, Massachusetts, 1987.

Lehmann, J. "A handful of carbon," Nature (447) 2007, pp 143-144.

Lovegrove, K., Luzzi, A., Soldiani, I., and Kreetz, H. "Developing ammonia based thermochemical energy storage for dish power plants," Solar Energy (76:1-3), January-March 2004, pp 331337.

Norum, K.E. "Appreciative Design," Systems Research and Behavioral Science (18) 2001, pp 323333.

Ölz, S., Sims, R., and Kirchner, N. "Contribution of Renewables to Energy Security."

Orlikovski, W.J. "Material knowing: the scaffolding of human knowledgeability," European Journal of Information Systems (15) 2006, pp 460-466.

Patnaik, D., and Becker, R. "Needfinding: The Why and How of Uncovering People's Needs," Design Management Journal (10:2) 1999, pp 37-43.

Somerville, C. "Biofuels," Current Biology (17:4), 20 February 2007 2007, pp R115-R119.

Ståhlbröst, A. "Human-Centric Evaluation of Innovation," in: Department of Business Administration and Social Sciences, Luleå University of Technology, Luleå, 2006.

Ståhlbröst, A., and Bergvall-Kåreborn, B. "FormIT - An Approach to User Involvement," in: European Living Labs - A New Approach for Human Centric Regional Innovation, J. Schumacher and V.-P. Niitamo (eds.), Wissenschaftlicher Verlag Berlin Olaf Gaudig \& Peter Veit GbR, Berlin, 2007a, pp. 63-76. 
Ståhlbröst, A., and Bergvall-Kåreborn, B. "Unveiling the Mysterious Needs of Users " 30th Information Systems Research Seminar in Scandinavia, IRIS30, Department of Computer Sciences, University of Tampere, Finland, Tampere, Finland, 2007b.

Ståhlbröst, A., and Holst, M. "Appreciating Needs for Innovative IT Design," International Journal of Knowledge, Culture and Change Management (6:4) 2006, pp 37-46.

Ståhlbröst, A., Mirijamdotter, A., and Bergvall-Kåreborn, B. "Needs and Accommodation in Evaluation Design," 12th European Conference on Information Technology Evaluation (ECITE 2005), Turku, Finland, 2005, pp. 457-464.

Stern, N. "The Economics of Climate Change," American Economic Review (98:2) 2008, pp 1-37.

Tenenbaum, D.J. "Food vs. Fuel: Diversion of Crops Could Cause More Hunger," Environ Health Perspective (116:6) 2008, pp A254-A257.

Thomas, G., and Fernández, W. "Success in IT projects: A matter of definition?," International Journal of Project Management (26:7) 2008, pp 733-742.

Tiitta, S. "Identifying elderly people's needs for communication and mobility," Include 2003 (7:March) 2003, pp 266-271.

Ulrich, W. "Critical Heuristics of Social Systems Design," European Journal of Operational Research (31) 1987, pp 276-283.

Ulrich, W. "Systems Thinking as if People Mattered," Working Paper No. 23., Centre for Systems Research, Lincoln School of Management, University of Lincolnshire and Humberside, Lincoln.

Witze, A. "That's oil, folks....," Nature (445) 2007, pp 14-17. 